\title{
IMPACTOS DA CONSTRUÇÃO DO PORTO DE SUAPE SOBRE A COMUNIDADE FITOPLANCTÔNICA NO ESTUÁRIO DO RIO IPOJUCA (PERNAMBUCO-BRASIL)
}

\author{
Maria Luise Koening ${ }^{1}$ \\ Enide Eskinazi-Leça ${ }^{2}$ \\ Sigrid Neumann-Leitão ${ }^{1}$ \\ Silvio José de Macêdo ${ }^{1}$
}

Recebido em 23/11/2000. Aceito em 04/04/2002.

\begin{abstract}
RESUMO - (Impactos da construção do Porto de Suape sobre a comunidade fitoplanctônica no estuário do rio Ipojuca, Pernambuco, Brasil). A construção do Complexo Industrial Portuário de Suape, entre os anos de 1979/84, modificou as características ecológicas da área, sendo os maiores impactos observados no estuário do rio Ipojuca. Visando avaliar a ação desses impactos sobre a comunidade fitoplanctônica através da comparação com estudos realizados antes na área, foram analisadas amostras de plâncton coletadas em uma estação, durante um ciclo de 24 horas, nos períodos chuvoso (agosto/90) e seco (janeiro/91). As amostras foram coletadas pela técnica do fracionamento e com rede de plâncton de $65 \mu \mathrm{m}$ de abertura de malha. Coletas de parâmetros hidrológicos foram realizadas concomitantemente. Foram identificados 97 táxons, destacando-se como espécies muito freqüentes nos períodos chuvoso e seco: Gyrosigma balticum, Oscillatoria princeps, Chaetoceros lorenzianus, Climacosphenia moniligera e Licmophora abbreviata. A densidade fitoplanctônica variou entre 142.000 cels..$^{-1}$ a 1.789 .000 cels. $^{-1}$ predominando a fração do nanofitoplâncton. O maior florescimento ocorreu no período seco, nos horários de maior insolação e maré enchente. A diversidade específica foi alta $\left(>3\right.$ bits.cel..$\left.^{-1}\right)$ explicada pela heterogeneidade ambiental. A comunidade fitoplanctônica apresentou mudanças quali-quantitativas após a implantação do Porto. Agora, predominam espécies marinhas litorais, devido à pequena profundidade e elevado hidrodinamismo na área e um decréscimo de $70 \%$ na densidade celular, ao contrário do que ocorria antes da construção do Porto, quando foi detectado a maior ocorrência de espécies marinhas planctônicas e maior número de células/litro.
\end{abstract}

Palavras-chave - Fitoplâncton, ecologia, variação nictemeral, impacto

\begin{abstract}
Impacts of the construction of the Port of Suape on the phytoplankton community in the Ipojuca River Estuary, Pernambuco, Brazil). The Suape Industrial Port Complex (Pernambuco-Brazil) constructed between 1979/84 modified the ecology of the area, causing great impacts in the Ipojuca River. In order to assess the impacts on the phytoplankton community comparing with previous studies, samples were obtained at one fixed station in August/90 (rainy season) and in January/91 (dry season). Collections were made in a nyctemeral cycle, every 2 hours by the fraction method and with a plankton net $65 \mu \mathrm{m}$ mesh size. Hydrological data were collected simultaneously. 97 taxa were identified and the most frequent at both studied period were: Gyrosigma balticum,
\end{abstract}

\footnotetext{
${ }^{1}$ Departamento de Oceanografia da Universidade Federal de Pernambuco- Av.Arquitetura s/n-Cidade Universitária. 50.740.550, e-mail: Koening@npd.ufpe.br

${ }^{2}$ Departamento de Biologia da Universidade Federal Rural de Pernambuco, e-mail: enide@elogia.com.br
} 
Oscillatoria princeps, Chaetoceros lorenzianus, Climacosphenia moniligera and Licmophora abbreviata. Phytoplankton densities ranged from 142,000 cells..$^{-1}$ to $1,789,000$ cells. $1^{-1}$ predominating the nanoplankton fraction, being higher in the dry season, during periods of intense sunlight and flood tide. Species diversity was high (> 3 bits.cel. $1^{-1}$ ), explained by the environment heterogeneity. The phytoplankton community changed after port construction. Now, there are many littoral species due to the shallow depth and high hydrodinamism of the area and a decrease of $70 \%$ in cell density compared to the results obtained before port construction where predominated planktonic species and higher number of cells liter.

Key words - Phytoplankton, ecology, nyctemeral variation, impact

\section{Introdução}

O Governo do Estado de Pernambuco elaborou, entre 1973 e 1976, um Plano Diretor para a implantação de um Complexo Industrial Portuário, na área de Suape, localizada ao sul da cidade do Recife, com funções industriais e comerciais. Este plano surgiu como uma forma de solução ao crescimento econômico do Estado. A fim de evitar maiores riscos e danos à área, foi desenvolvido um programa de pesquisas sobre impactos ambientais. Esse programa teve início com um Estudo de Impacto Ambiental, antes da implantação do Porto, em 1977, patrocinado pelo próprio Governo do Estado.

Os resultados destes estudos, publicados em Melo Filho (1977), Lima (1978), Lima \& Costa (1978), Cavalcanti et al. (1980), CONDEPE (1983), Eskinazi-Leça \& Koening (1985/1986), Paranaguá (1985/1986), Neumann-Leitão (1986), Vasconcelos Filho et al. (1990), além de outros estudos realizados anteriormente na região (Melo 1958; Cobra 1967; Maciel 1968; Mello \& Siqueira 1972; Santos \& Costa 1974; Costa \& Costa 1977; Amaral \& Menor 1979), contribuíram para um conhecimento geral das condições ecológicas do meio, tendo sido feitas sugestões para que os impactos fossem minimizados, bem como forneceram orientações para um monitoramento adequado.

Visando um acompanhamento das modificações ao longo da implantação deste complexo portuário, o Departamento de Oceanografia da Universidade Federal de Pernambuco (UFPE), teve a iniciativa de realizar estudos ecológicos detalhados, que enfocaram principalmente o estuário do rio Ipojuca, que drena maior volume d'água e foi o mais impactado.

Como parte integrante desses estudos, o da comunidade fitoplanctônica do estuário do rio Ipojuca foi priorizado, uma vez que, por constítuírem o primeiro elo da cadeia trófica, contribuem substancialmente para a produção primária total e maior fonte de alimento para animais na coluna d'água e nos sedimentos (Day Jr et al. 1989), respondendo rapidamente aos impactos ambientais, sendo excelentes bioindicadores (Loeb \& Spacie 1994).

Estudos sobre o fitoplâncton antes da implantação do Porto foram realizados por Eskinazi-Leça \& Koening (1985/86); Koening \& Eskinazi-Leça (1991) e Koening et al. (1996). O presente trabalho teve por objetivo caracterizar a estrutura do fitoplâncton e identificar as possíveis modificações ocorridas em consequiência da implantação do referido Porto.

Descrição da Área

O estuário do rio Ipojuca está localizado a cerca de $40 \mathrm{~km}$ ao sul da cidade do Recife, Estado de Pernambuco $\left(08^{\circ} 15^{\prime} 00^{\prime \prime}\right.$ e $08^{\circ} 30^{\prime} 00^{\prime \prime} \mathrm{S}, 3^{\circ} 55^{\prime} 00^{\prime \prime}$ e $\left.35^{\circ} 05^{\prime} 00^{\prime \prime} \mathrm{W}\right)$. O rio Ipojuca nasce na Serra do Pau D' Arco no município de Arcoverde. Sua bacia hidrográfica total é de $3.800 \mathrm{~km}^{2}$, tendo sua área estuarina extensão aproximada de 15 Km. Até atingir o Oceano Atlântico, percorre duas regiões fitogeográficas, sendo temporário na região do Agreste e perene na zona da Mata (CONDEPE 1980).

O clima é quente e úmido pseudo-tropical, do tipo As', segundo Köppen. O regime 
pluviométrico varia entre 1.850 a $2.364 \mathrm{~mm}$ anuais. A temperatura média anual é de $24^{\circ} \mathrm{C}$, umidade relativa média anual superior a $80 \%$ e predominam os ventos de sudeste (Nimer 1979). O Ipojuca recebe forte carga poluidora, pois nenhuma das cidades da sua bacia possui sistema adequado de esgoto sanitário havendo, em algumas, pequenas extensões de redes coletoras com inadequada disposição final. A carga orgânica de nove cidades da bacia, bem como o potencial poluidor foi estimado em 21.861 kg DBO.dia ${ }^{-1}$, para 1990 ( CPRH 1995).

No que se refere a vegetação Braga et al. (1989) mencionaram que o manguezal sofreu um processo de degradação acentuado, decorrente de aterros, dragagens e represamentos com a implantação do porto, com cerca de 600 hectares destruídos.

Com construção de molhes para atracagem dos navios no Complexo Portuário foi bloqueada a comunicação dos rios Ipojuca e Merepe com o mar, ocasionando inundações nas áreas utilizadas pela agroindústria da cana-de-açúcar. Para minimizar esse impacto, uma abertura foi feita no próprio recife, próxima à desembocadura do rio Ipojuca, para permitir a penetração do mar. Como consequiência, constatou-se um retardo de mais de duas horas na maré dinâmica, registrando-se atualmente 8 horas de baixa-mar e apenas 4 horas de preamar ao invés dos ciclos normais de 6 horas. As marés apresentam amplitude máxima em torno de 2 metros na desembocadura. As modificações provocaram ainda um forte assoreamento e grande deposição de sedimentos em suspensão na área estuarina, aumentando a turbidez da água e transformando a foz do estuário do rio Ipojuca numa laguna costeira que, em consequiência da diminuição da profundidade local, causou aumento da salinidade (Neumann 1991; Neumann et al. 1998).

\section{Material e métodos}

As coletas foram realizadas numa estação fixa (Estação 1) localizada no estuário do rio
Ipojuca, a 0,5 km do recife costeiro (Fig. 1). As amostragens foram efetuadas na superficie, nos períodos chuvoso (agosto/1990) e seco (janeiro/ 1991), num ciclo de 24 horas, a cada uma hora para as variáveis abióticas e duas horas para o fitoplâncton.

Os seguintes dados abióticos foram obtidos: profundidade local (m), transparência da água (m) (disco de Secchi) e coeficiente de extinção da luz (empregando-se a fórmula de Poole \& Atkins 1929: k=1,7/d, onde 1,7 é a constante calculada e $\mathrm{d}$ a profundidade de desaparecimento do disco de Secchi), temperatura da água $\left({ }^{\circ} \mathrm{C}\right)$ (termômetro de reversão acoplado à garrafa tipo Nansen), salinidade(S) (método Mohr-Knudsen), oxigênio dissolvido (ml. $\mathrm{l}^{-1}$ ) (método de Winkler), teor de saturação do oxigênio dissolvido (\%), pH (potenciômetro Beckman Zeromatic II); e nutrientes $\left(\mu \mathrm{mol}^{1} \mathrm{l}^{-1}\right)$ que foram determinados pelos métodos descritos por Strickland \& Parsons (1972), Grasshoff et al. (1983) e Unesco (1973).

O fitoplâncton foi coletado pela técnica do fracionamento (Koening, 1983), tendo sido filtrados 60 litros de água, com o auxílio de uma tela com abertura de malha de $45 \mu \mathrm{m}$, permitindo o fracionamento do fitoplâncton em duas frações: $>45 \mu \mathrm{m}$ (microfitoplâncton), sendo as amostras fixadas imediatamente com formol neutro a $4 \%$; e $<45 \mu$ m (nanofitoplâncton), fixadas com 1 a 2 $\mathrm{ml}$ da solução de Lugol. A quantificação do fitoplâncton (células por litro) foi realizada em microscópio invertido marca, WILD M-40 (Hasle 1978; Edler 1979; Ferrario et al. 1995) utilizandose o método de transecção, com aumento de 450x para a fração do nanofitoplâncton e 100x para o microfitoplâncton.

Foram feitos também arrastos horizontais superficiais, durante 5 minutos, com rede de plâncton, de tecido de náilon, com abertura de malha de $65 \mu \mathrm{m}$ para a identificação dos taxa. As microalgas foram identificadas com o auxílio de bibliografia especializada. A identificação dos fitoflagelados ficou à nível de classe, uma vez que requer um estudo de microscopia eletrônica. 


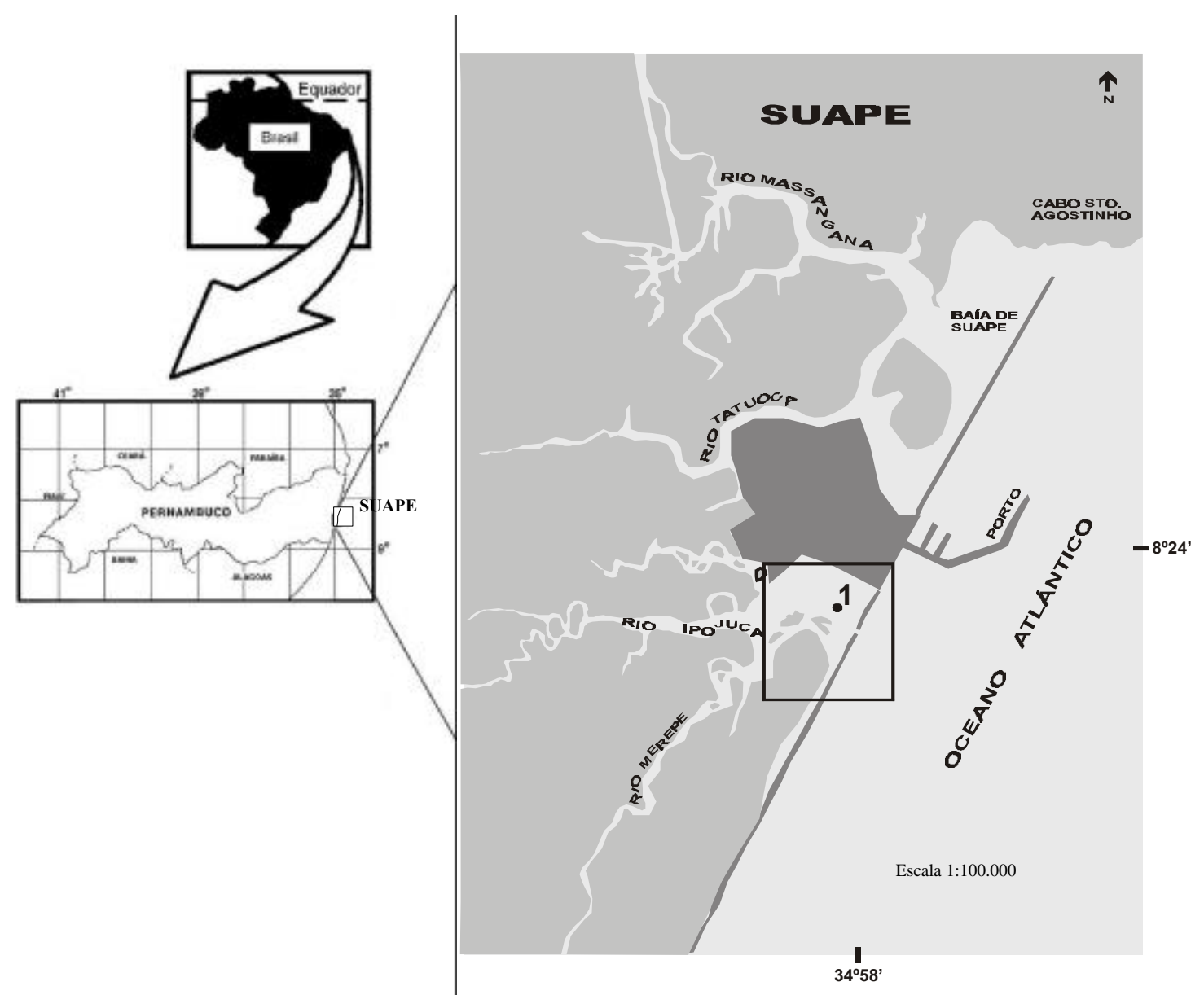

Figura 1. Área estudada e estação de coleta nolestuário do rio Ipojuca, PE (Brasil).

Para atualização nomenclatural das diatomáceas, foram utilizadas as publicações de Hasle (1983) e Lange et al. (1992) e o trabalho de Hasle \& Syvertsen (1997). Para o reconhecimento dos dados ecológicos das espécies, seguiu-se Moreira Filho et al. (1990; 1994/95).

A diversidade específica foi baseada no índice de Shannon (1948).

Para o agrupamento das espécies a matriz de dados foi espécies/amostras, contendo a abundância relativa de cada espécie, aplicandose o coeficiente de dissimilaridade de BrayCurtis e utilizando o método de ligação do peso proporcional para o dendrograma (Legendre \& Legendre 1984). Uma matrix de valores cofenéticos foi aplicada para testar o ajuste dos dados da análise de agrupamento (Rohlf \& Fisher 1968).

Para o agrupamento das amostras foram levados em consideração os taxa fitoplanctônicos com mais de $70 \%$ de ocorrência e os parâmetros ambientais mais significativos, tendo-se procedido uma padronização por fileiras para reduzir o efeito das diferentes escalas. Em seguida, foi feita uma transformação logaritimica $(\log x+1)$ e aplicado o coeficiente de correlação momento produto de Pearson. Para o agrupamento das amostras foi utilizado o método de ligação do peso proporcional para o dendrograma (Legendre \& Legendre 1984) e em seguida foi aplicada uma matriz de valores cofenéticos para testar o ajuste dos dados da análise de agrupamento (Rohlf \& Fisher 1968). 
Para estas análises foi utilizado programa computacional NTSYS (Numerical Taxonomy and Multivariate Analysis System) da Metagraphics Software Corporation, California - USA.

\section{Resultados}

\section{Variáveis abióticas}

Durante o período chuvoso, a transparência da água apresentou uma variação bastante característica, estando os valores mínimos relacionados com os períodos de baixamar, ocasião em que a quantidade de material em suspensão na água é mais acentuada. O valor mínimo de 0,40 m (4,25 de coeficiente de extinção da luz), foi registrado às 14:30 h e o máximo de $2,00 \mathrm{~m}(0,85$ de coeficiente de extinção da luz), ocorreu às 5:30 h. No período seco, os valores de transparência foram mais elevados e oscilaram entre 0,53 m (2,27\% de coeficiente de extinção da luz), às $13: 00 h$ a 2,00 às $6: 00(0,85 \%$ de coeficiente de extinção da luz).

A salinidade apresentou amplas variações, caracterizando o ambiente de oligoalino a eualino $(4,17 \mathrm{~S}$ às $1: 30 \mathrm{~h}$ e $36,45 \mathrm{~S}$ às $5: 30 \mathrm{~h})$ no período chuvoso e mesoalino a eualino $(11,5 \mathrm{~S}$ às $21: 00 \mathrm{~h}$ e 3:00 h e 37,18S às 5:00 h) no período seco.

As concentrações de oxigênio dissolvido no período chuvoso variaram de condições supersaturadas a de saturação normal na maioria dos horários, estando os valores entre 3,83 ml.1 $\mathrm{l}^{-1}$ (percentual de saturação de 70,97\%) às 1:30 h e $5,85 \mathrm{ml}^{-1} \mathrm{l}^{-1}(127,45 \%)$ às $6: 30 \mathrm{~h}$. Já no período seco, estas concentrações apresentaram valores mais baixos, principalmente, durante a maré vazante e baixa-mar. Os valores variaram de condições semi-anóxicas a supersaturadas, estando os valores entre $0,32 \mathrm{ml}^{-1} \mathrm{l}^{-1}(6,87 \%)$ às 13:00 h a 5,53 ml.1-1 $(123,71 \%)$ às 6:00 h.

Os valores de sais nutrientes apresentaram oscilações bastante significativas em ambos os períodos. As concentrações de Nitrito-N oscilaram no período chuvoso entre $0,020 \mu \mathrm{mol}^{-1} \mathrm{I}^{-1}$ às $19: 30 \mathrm{~h}$ e $0,160 \mu \mathrm{mol}^{-1} \mathrm{I}^{-1}$ às $14: 30 \mathrm{~h}$ e no período seco, entre de $0,001 \mu$ mol. $1^{-1}$ às $18: 00 h$ e $1,344 \mu$ mol. $^{-1}$ à 1:00h. Os valores mais elevados coincidiram com o período de baixa-mar. As concentrações de Nitrato-N oscilaram entre $0,022 \mu \mathrm{mol}^{-1} \mathrm{l}^{-1}$ às $5: 30 \mathrm{~h}$ e $8,163 \mu \mathrm{mol} . \mathrm{l}^{-1}$ às $21: 30 \mathrm{~h}$. $\mu$ mol. $\mathrm{l}^{-1}$ no período chuvoso e entre $699 \mu \mathrm{mol}^{-1} \mathrm{l}^{-1}$ às $12: 00 \mathrm{~h}$ e 3,429 $\mu$ mol. $1^{-1}$ às 21:00 h no período seco. Observa-se também uma tendência destas concentrações de aumentarem com a baixa-mar em ambos os períodos. Já o Fosfato-P variou de 0,193 $\mu$ mol. $\mathrm{l}^{-1}$ às $5: 30 \mathrm{~h} \mathrm{a} 1,301 \mu \mathrm{mol} . \mathrm{l}^{-1}$ às $13: 30 \mathrm{~h}$ no período chuvoso e de $0,366 \mu \mathrm{mol}^{-1} \mathrm{l}^{-1}$ às 7:00 $\mathrm{h}$ a $0,962 \mu \mathrm{mol}^{-1} \mathrm{l}^{-1}$ às 11:00 e 1:00 h no período seco. As concentrações de Silicato-Si foram elevadas e oscilaram no período chuvoso entre 14,562 $\mu$ mol. $\mathrm{l}^{-1}$ às $5: 30 \mathrm{~h} \mathrm{e} 130,408 \mu \mathrm{mol} . \mathrm{l}^{-1}$ às $14: 30 \mathrm{~h}$. Observou-se uma tendência destas concentrações aumentarem com a baixa-mar neste período, demonstrando uma forte influência do material alóctone na estação estudada. No período seco, as concentrações de Silicato-Si oscilaram de $19,986 \mu$ mol. $1^{-1}$ às 6:00 h a $141,661 \mu$ mol. l $^{-1}$ às 13:00 h (Tab. 1).

\section{Composição Fitoplanctônica.}

Durante o ciclo nictemeral, foram identificados 97 táxons representados pelas Divisões: Cyanophyta (8 espécies), Euglenophyta (1 espécie), Pyrrophyta (11 espécies e 1 variedade), Chrysophyta (69 espécies, 1 forma e 1 variedade) e Chlorophyta (5 espécies). O maior número de espécies ocorreu no período chuvoso, quando foram registradas 74 espécies, 2 variedades e 1 forma. No período seco, foram identificadas 70 espécies (Tab. 2).

Das 97 espécies identificadas apenas 5 (cinco), foram consideradas muito frequientes tanto no período seco como chuvoso, destacando-se Gyrosigma balticum, presente em 100,00\% das amostras, Oscillatoria princeps, Chaetoceros 
Tabela 1. Dados hidrológicos no estuário do rio Ipojuca, durante o período chuvoso (agosto/90) e seco (janeiro/91)

\begin{tabular}{|c|c|c|c|c|c|c|c|c|c|c|}
\hline \multirow[t]{2}{*}{ PERÍODO } & \multirow[t]{2}{*}{ HORA } & \multirow[t]{2}{*}{$\begin{array}{l}\text { Transpa- } \\
\text { rência } \\
\text { (m) }\end{array}$} & \multirow[t]{2}{*}{$\begin{array}{c}\text { Coef. } \\
\text { Extinção } \\
\text { Luz }\end{array}$} & \multirow[t]{2}{*}{$\begin{array}{c}\text { Salinidade } \\
\text { S }\end{array}$} & \multirow[t]{2}{*}{$\begin{array}{c}\mathrm{O} 2 \text { dissolvido } \\
\mathrm{ml} . \mathrm{l}^{-1}\end{array}$} & \multirow[t]{2}{*}{$\begin{array}{c}\mathrm{O} 2 \text { dissolvido } \\
\%\end{array}$} & \multirow[t]{2}{*}{$\begin{array}{l}\text { Nitrito } \\
\text { N-NO2 } \\
\mu \text { mol.1.1 }^{-1}\end{array}$} & \multirow[t]{2}{*}{$\begin{array}{l}\text { Nitrato } \\
\text { N-NO3 } \\
\mu \text { mol.1 }^{-1}\end{array}$} & \multirow[t]{2}{*}{$\begin{array}{l}\text { Fosfato } \\
\text { P-PO4 } \\
\mu{\mathrm{mol} .1^{-1}}^{-1}\end{array}$} & \multirow[t]{2}{*}{$\begin{array}{l}\text { Silicato } \\
\text { S-SIO2 } \\
\mu \text { mol.1 }^{-1}\end{array}$} \\
\hline & & & & & & & & & & \\
\hline & $5: 30$ & 2,00 & 0,85 & 36,41 & 5,27 & 113,58 & 0,080 & 0,022 & 0,506 & 14,562 \\
\hline & $6: 30$ & 1,80 & 0,94 & 36,10 & 5,85 & 127,45 & 0,040 & 2,360 & 0,482 & 23,021 \\
\hline & $7: 30$ & 1,20 & 1,42 & 35,30 & 5,00 & 108,46 & 0,090 & 1,440 & 0,675 & 16,917 \\
\hline & $8: 30$ & 1,10 & 1,55 & 30,21 & 4,84 & 102,33 & 0,120 & 2,611 & 0,675 & 34,008 \\
\hline & $9: 30$ & 1,00 & 1,70 & 21,39 & 5,43 & 110,14 & 0,080 & 2,921 & 1,012 & 58,642 \\
\hline & $10: 30$ & 0,80 & 2,13 & 22,00 & 4,68 & 95,51 & 0,140 & 3,954 & 0,988 & 84,802 \\
\hline $\mathrm{C}$ & $11: 30$ & 0,70 & 2,43 & 17,20 & 5,00 & 100,00 & 0,100 & 4,919 & 1,181 & 84,104 \\
\hline $\mathrm{H}$ & $12: 30$ & 0,60 & 2,83 & 14,00 & 4,58 & 90,69 & 0,130 & 5,119 & 1,205 & 90,993 \\
\hline $\mathrm{U}$ & $13: 30$ & 0,50 & 3,40 & 11,70 & 4,58 & 91,05 & 0,130 & 6,866 & 1,301 & 71,199 \\
\hline $\mathrm{V}$ & $14: 30$ & 0,40 & 4,25 & 12,60 & 5,16 & 101,78 & 0,160 & 4,807 & 1,157 & 130,408 \\
\hline $\mathrm{O}$ & $15: 30$ & 0,60 & 2,83 & 28,61 & 5,21 & 111,80 & 0,050 & 2,077 & 0,434 & 28,427 \\
\hline$S$ & $16: 30$ & 0,80 & 2,13 & 36,00 & 5,27 & 117,08 & 0,060 & 2,450 & 0,530 & 42,510 \\
\hline \multirow[t]{16}{*}{$\mathrm{O}$} & $17: 30$ & & & 35,80 & 5,11 & 115,87 & 0,060 & 2,330 & 0,506 & 35,220 \\
\hline & $18: 30$ & & & 30,80 & 5,00 & 108,46 & 0,040 & 2,610 & 0,520 & 38,400 \\
\hline & $19: 30$ & & & 22,99 & 4,79 & 99,38 & 0,020 & 2,110 & 0,434 & 46,957 \\
\hline & $21 ; 30$ & & & 10,03 & 5,32 & 102,31 & 0,030 & 8,163 & 0,940 & 68,124 \\
\hline & $23: 30$ & & & 6,61 & 4,15 & 77,86 & 0,080 & 3,396 & 0,530 & 26,753 \\
\hline & $1: 30$ & & & 4,17 & 3,83 & 70,93 & 0,050 & 2,869 & 0,482 & 30,476 \\
\hline & $3: 30$ & & & 21,92 & 4,89 & 98,19 & 0,030 & 2,517 & 0,578 & 36,232 \\
\hline & $5: 30$ & & & 36,45 & 4,47 & 98,03 & 0,050 & 2,081 & 0,193 & 22,759 \\
\hline & $5: 00$ & & & 37,18 & 5,38 & 124,83 & 0,055 & 2,495 & 0,412 & 35,614 \\
\hline & $6: 00$ & 2,00 & 0,85 & 35,85 & 5,53 & 123,71 & 0,033 & 2,043 & 0,481 & 19,986 \\
\hline & $7: 00$ & 1,60 & 1,06 & 19,52 & 5,16 & 105,31 & 0,055 & 2,220 & 0,366 & 22,835 \\
\hline & $8: 00$ & 1,30 & 1,31 & 36,91 & 4,90 & 110,11 & 0,022 & 2,000 & 0,641 & 28,533 \\
\hline & $9: 00$ & 1,20 & 1,42 & 32,66 & 4,32 & 95,36 & 0,087 & 3,256 & 0,687 & 25,516 \\
\hline & $10: 00$ & 1,15 & 1,48 & 35,32 & 3,69 & 83,48 & 0,044 & 1,291 & 0,870 & 49,567 \\
\hline & $11: 00$ & 1,10 & 1,55 & 27,88 & 3,27 & 71,08 & 0,033 & 1,895 & 0,962 & 74,077 \\
\hline & $12 ; 00$ & 0,75 & 2,27 & 24,17 & 2,53 & 54,18 & 0,044 & 0,699 & 0,549 & 92,262 \\
\hline $\mathrm{S}$ & $13: 00$ & 0,53 & 2,27 & 22,84 & 0,32 & 6,87 & 0,044 & 1,044 & 0,687 & 141,661 \\
\hline $\mathrm{E}$ & $14: 00$ & 0,90 & 3,21 & 25,49 & 2,64 & 57,39 & 0,033 & 0,987 & 0,504 & 40,181 \\
\hline $\mathrm{C}$ & $15: 00$ & 1,90 & 1,89 & 26,56 & 3,37 & 73,58 & 0,011 & 1,272 & 0,824 & 120,669 \\
\hline \multirow[t]{8}{*}{$\mathrm{O}$} & $16: 00$ & & 0,89 & 29,83 & 5,27 & 115,06 & 0,033 & 1,232 & 0,435 & 18,058 \\
\hline & $17: 00$ & & & 35,05 & 5,22 & 123,69 & 0,109 & 1,281 & 0,435 & 21,452 \\
\hline & $18: 00$ & & & 34,52 & 5,38 & 120,90 & 0,001 & 1,221 & 0,481 & 18,729 \\
\hline & $19: 00$ & & & 11,68 & 5,27 & 103,74 & 0,098 & 1,088 & 0,389 & 19,776 \\
\hline & $21 ; 00$ & & & 11,15 & 4,53 & 97,00 & 0,164 & 3,429 & 0,847 & 37,081 \\
\hline & $23: 00$ & & & 11,95 & 4,06 & 79,76 & 0,273 & 2,104 & 0,870 & 36,410 \\
\hline & $1: 00$ & & & 21,51 & 3,16 & 65,29 & 1,344 & 4,548 & 0,962 & 71,815 \\
\hline & $3: 00$ & & & 11,15 & 2,27 & 44,16 & 0,219 & 2,920 & 0,481 & 93,393 \\
\hline
\end{tabular}

lorenzianus, Climacosphenia moniligera e Licmophora abbreviata, em $80 \%$ das amostras.

Densidade $\left(\right.$ cel. $\left.^{-1}{ }^{-1}\right)$

A densidade fitoplanctônica total (Fig. 2), apresentou menores valores, no período chuvoso, com valor mínimo de 142.000 cel. $^{-1}{ }^{-1}$ às 19:30 h e máxi-

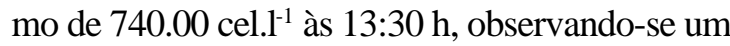
ciclo nictemeral com densidades ligeiramente mais elevadas nas horas de maior insolação, das 11:30 às 13:30 $\mathrm{h}$, coincidindo com a maré enchente. No que se refere às frações, predominou o nanofitoplâncton tendo os valores oscilado entre 75.000 cel..$^{-1}$ às $5: 30 \mathrm{~h}$ e 615.000 cel. $\mathrm{l}^{-1}$ às $13: 30 \mathrm{~h}$, apresentando um ciclo nictemeral semelhante à densidade total. Nesta fração, os fitoflagelados foram o grupo dominante, com 525.000 cel. $^{-1}{ }^{-1}$ às 13:00h. A fração do microfitoplâncton apresentou registro mínimo de 47.000 cel..$^{-1}$ às $17: 30$ he máximo de 188.000 cel. $^{-1}{ }^{-1}$ à $7: 30 \mathrm{~h}$, destacando-se o grupo das diatomáceas.No período seco, a densidade fitoplanctônica foi mais elevada, com valores oscilando entre o mínimo de 262.000 cel..$^{-1}$ às 3:00

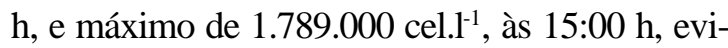
denciando dois ciclos diários, um com maiores concentrações das 11:00 às 15:00 h e outro, de 1:00 às 3:00 h, coincidindo com a maré enchente.

Quanto às frações, predominou o nanofitoplâncton, principalmente das 9:00 às 17:00 h, com 
Tabela 2. Lista dos taxa fitoplânctônicos no estuário do rio Ipojuca durante a estação chuvosa (agosto, 1990) e estação seca (janeiro, 1991).

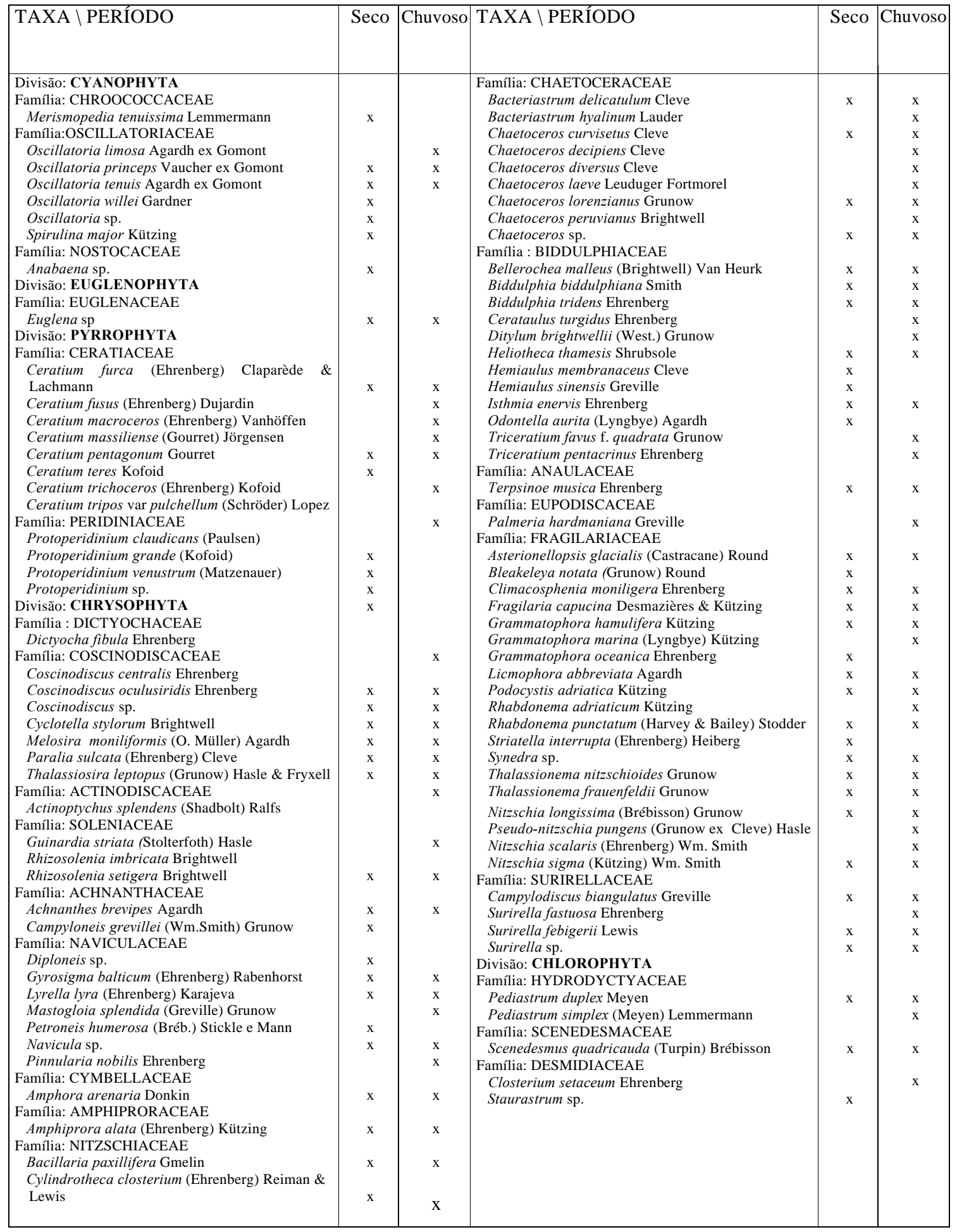




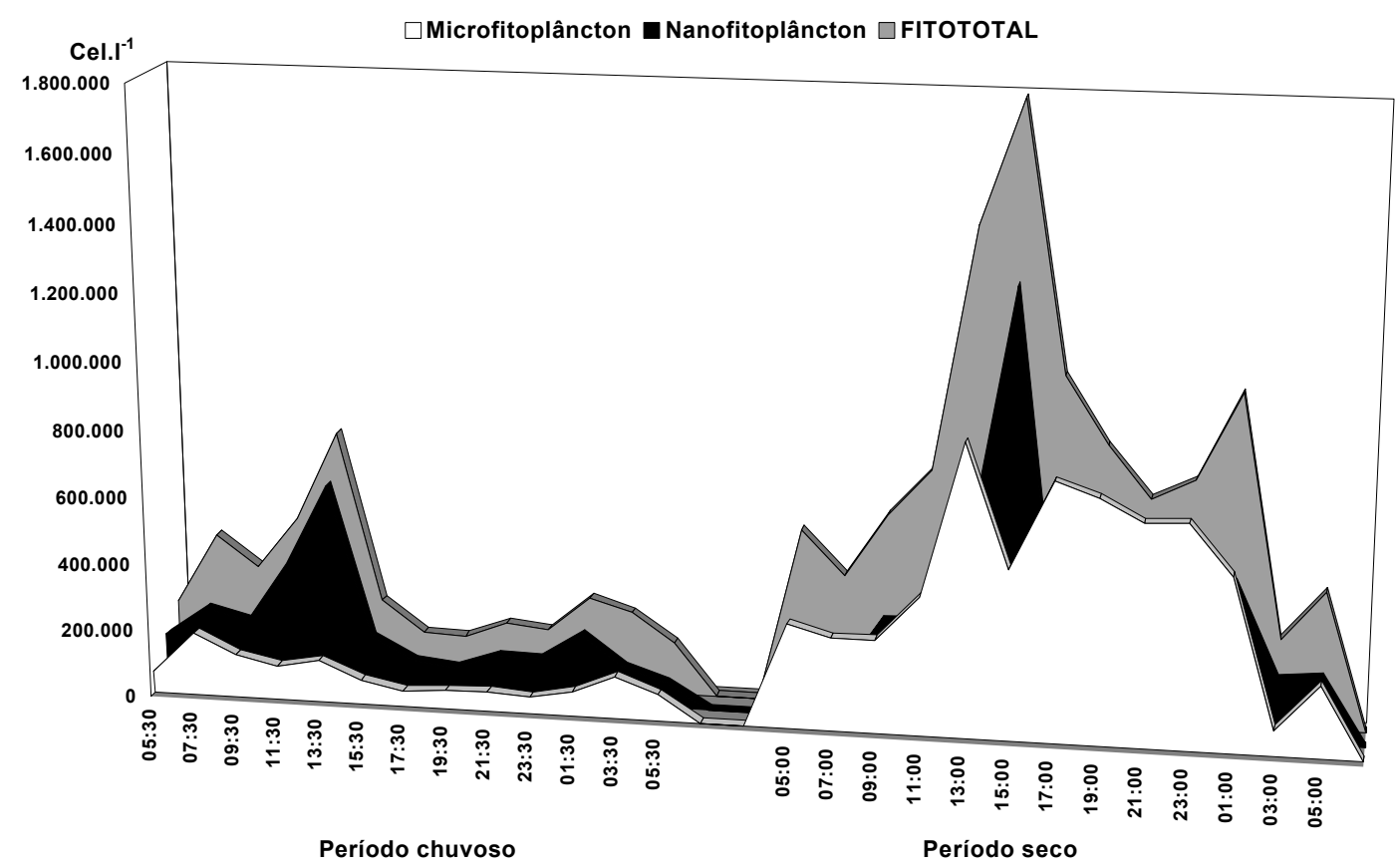

Figura 2. Densidade fitoplanctônica no estuário do rio Ipojuca, durante período chuvoso (agosto/90) e seco (janeiro/91).

mínimo de 5.000 cel. $1^{-1}$ às 23:00 h e máximo de 1.285.000 cel. $\mathrm{l}^{-1}$ às 15:00 h, sendo os valores mais elevados registrados nas horas de maior insolação, na baixa-mar e maré enchente, com um ciclo semelhante à densidade fitoplanctônica total. Nesta fração, também dominaram os fitoflagelados, com densidade máxima de 720.000 cel.1 1. A fração do microfitoplâncton, entretanto, apresentou maiores concentrações celulares das 13:00 à 1:00 h. $\mathrm{O}$ valor mínimo foi de 77.000 cel. $^{-1}$ às 3:00 h e máximo de 866.000 cel..$^{-1}$ às $13: 00$ h. As diatomáceas destacaram-se com densidade máxima de 718.000 cel. $^{-1}$ às 17:00 h, com maiores concentrações celulares na maré enchente. De uma maneira geral, a época de maior desenvolvimento fitoplanctônico ocorreu no período seco, nas horas de maior iluminação e durante a maré enchente.

\section{Diversidade específica}

A diversidade específica (Fig. 3) para ambos os períodos estudados, de uma maneira geral, foi relativamente alta. Das 13 amostras analisadas em cada período, $92,30 \%$ apresentaram valores superiores a 3,00 bits.cel ${ }^{-1}$, sendo apenas 7,70\% de diversidade média. A diversidade específica variou, no período chuvoso, de 2,93 bits.cel $^{-1}$ às 19:30 h a 4,49 bits.cel ${ }^{-1}$ às 7:30 h. No período seco, a diversidade mínima foi de 2,81 bits.cel ${ }^{-1}$ às 9:00 h e a máxima de 4,50 bits.cel ${ }^{-1}$ às 5:00 h. Não foram observadas diferenças entre os diferentes horários dos períodos chuvoso e seco. Esta maior diversidade deve-se à heterogeneidade ambiental, cujo estuário recebe influência dos fluxos marinho, limnético e do próprio manguezal, condicionando desta maneira, o maior aparecimento de espécies litorais. Deve-se levar em consideração, que, embora haja alta diversidade, as espécies são em sua maioria oportunistas (r-estrategistas) e não especialistas (k-estrategistas), o que indica um ambiente estuarino de baixa qualidade.

Associação das Espécies

A associação das espécies evidenciou dois grupos (Fig. 4). O grupo 1, o maior, com 83 


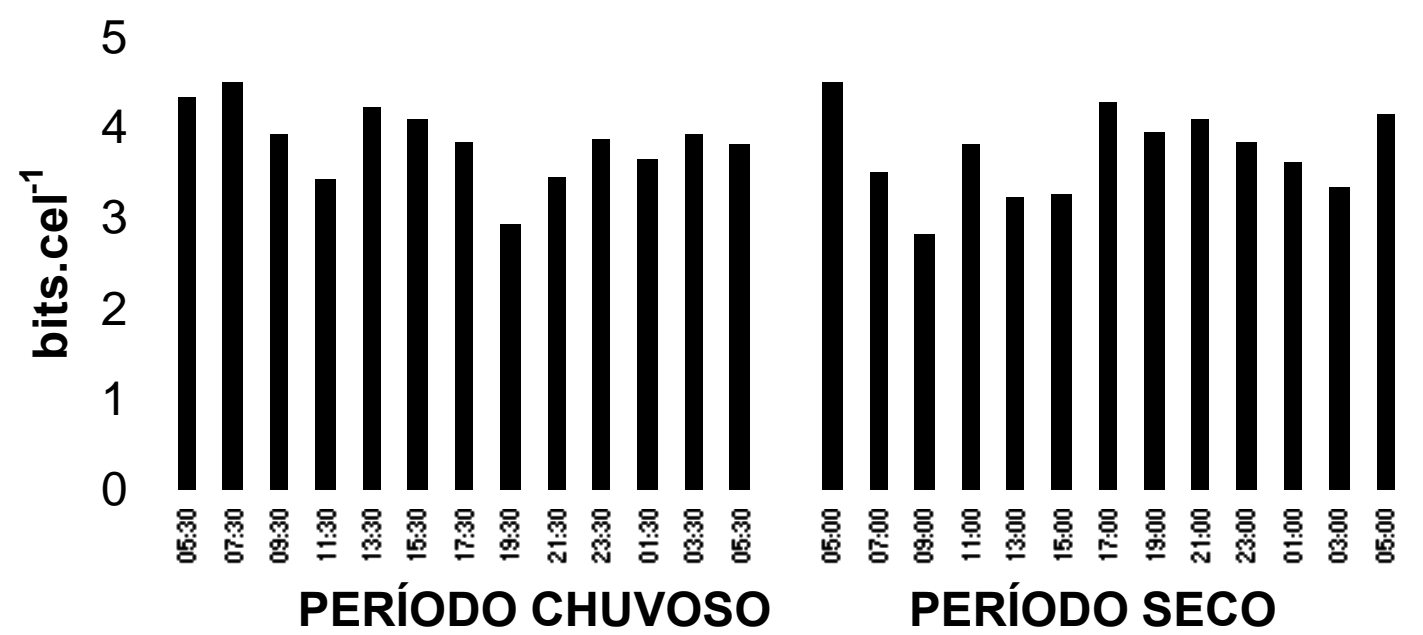

Figura 3. Diversidade específica no estuário do rio Ipojuca, durante os períodos chuvoso (agosto/90) e seco (janeiro/91).

espécies, compreendendo as espécies com menos de $50 \%$ de freqüência de ocorrência, formando um grupo bem misturado que reflete as próprias condições do estuário do rio Ipojuca. O grupo 2, formado por Gyrosigma balticum, Oscillatoria princeps, Chaetoceros lorenzianus, Climacosphenia moniligera, Licmophora abbreviata, Fragilaria capucina, Chaetoceros curvisetus, Coscinodiscus sp., Amphiprora alata, Cylindrotheca closterium, Melosira moniliformis, Oscillatoria sp., Biddulphia pulchella, Chaetoceros sp. além do grupo formado por diatomáceas não identificadas. Este grupo é formado por táxons comumente encontrados em áreas estuarinas.

\section{Associação das Amostras}

A associação das amostras (Fig. 5) permitiu evidenciar dois agrupamentos: o grupo 1, agrupou as amostras das preamares e marés enchentes dos períodos chuvoso e seco; o grupo 2 , compreendeu as amostras das baixa-mares e marés vazantes dos dois períodos. Pode-se constatar, que os regimes de marés tiveram maior influência na formação dos agrupamentos, do que as variações sazonais, destacando-se que no período estudado o regime pluviométrico foi atípico com baixas precipitações durante todo ano. Ressalta-se, ainda, que o grupo 2 apresentou maior número de horários, uma vez que o ciclo de marés foi alterado com o barramento parcial do rio Ipojuca, tendo a maré vazante maior duração.

\section{Discussão}

Todas as intervenções no meio ambiente geram impactos, positivos ou negativos, ocasionando alterações quali-quantitativas nos componentes florísticos e faunísticos, nas características geomorfológicas, sedimentológicas e hidrológicas.

No caso de Suape-PE, a quebra parcial dos recifes, para permitir a comunicação do mar com o rio Ipojuca, condicionou não só mudanças no ciclo das marés, como também manteve elevado os teores de salinidade e causou uma grande sedimentação na área, com consequiências na diminuição da transparência da água, fator fundamental para o desenvolvimento do fitoplâncton (Neumann-Leitão 1994; Neumann et al. 1998; Neumann-Leitão et al. 1999). 


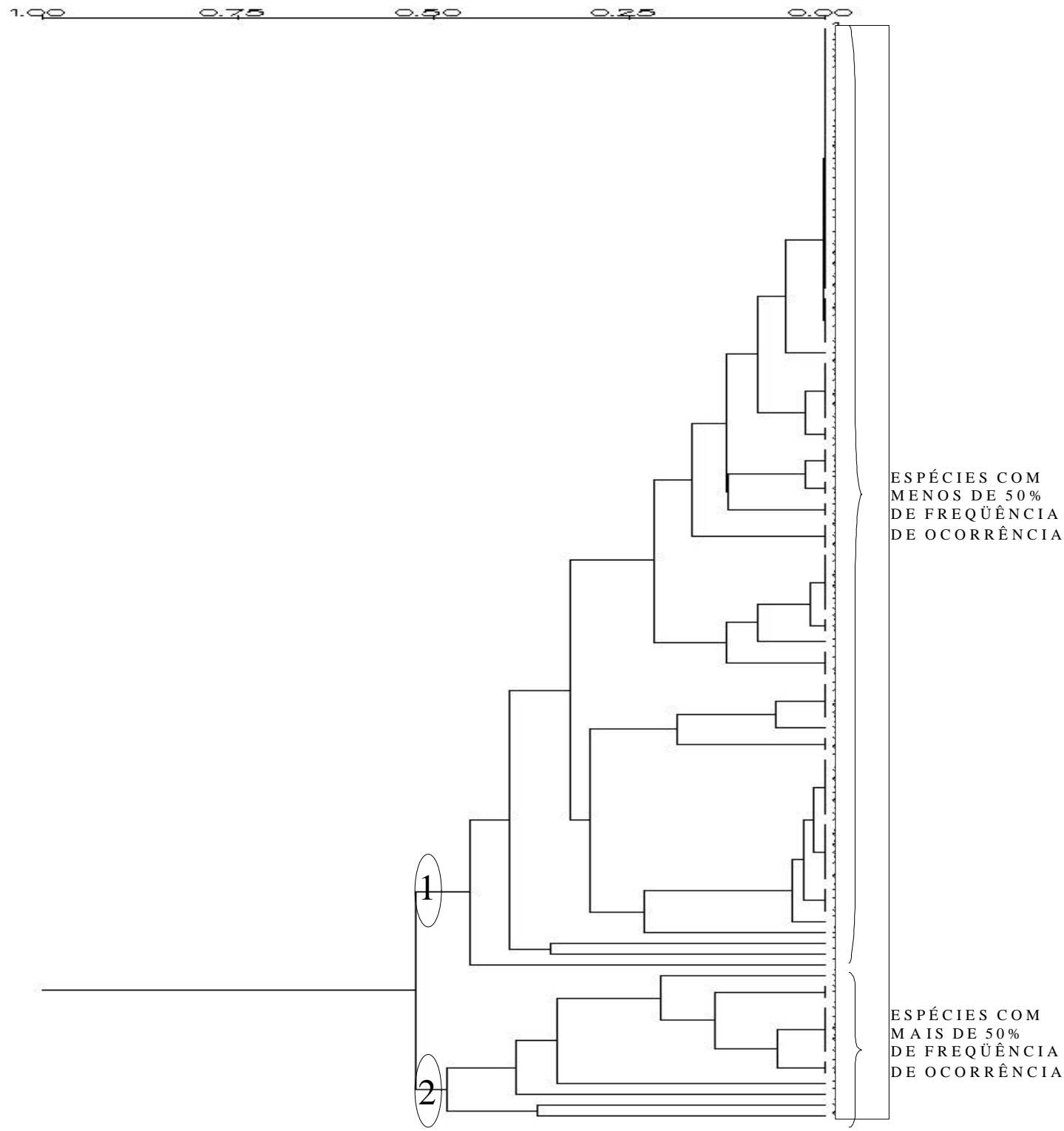

Figura 4. Dendrograma da associação das espécies do fitoplâncton que ocorreram com mais de $10 \%$ de frequiência de ocorrência, no estuário do rio Ipojuca, durante o período chuvoso (agosto/90) e seco (janeiro/91).

O alto grau de instabilidade ambiental resultante desses impactos antrópicos modificou a estrutura da comunidade fitoplanctônica, condicionando o maior aparecimento de espécies litorais (epífitas e bentônicas) que, em virtude da pequena profundidade decorrente da grande sedimentação na área e dos processos de ressuspensão, predominaram no ecossistema com percentual de $28,88 \%$, enquanto que as espécies planctônicas estiveram em torno de $16,30 \%$. Além do mais, a heterogeneidade ambiental teve importante papel na alta diversidade das espécies pois foram trazidas para o estuário espécies marinhas, limnéticas e litorais.

A grande disponibilidade de nutrientes e a salinidade alta permitiram, ainda, o desenvolvi- 


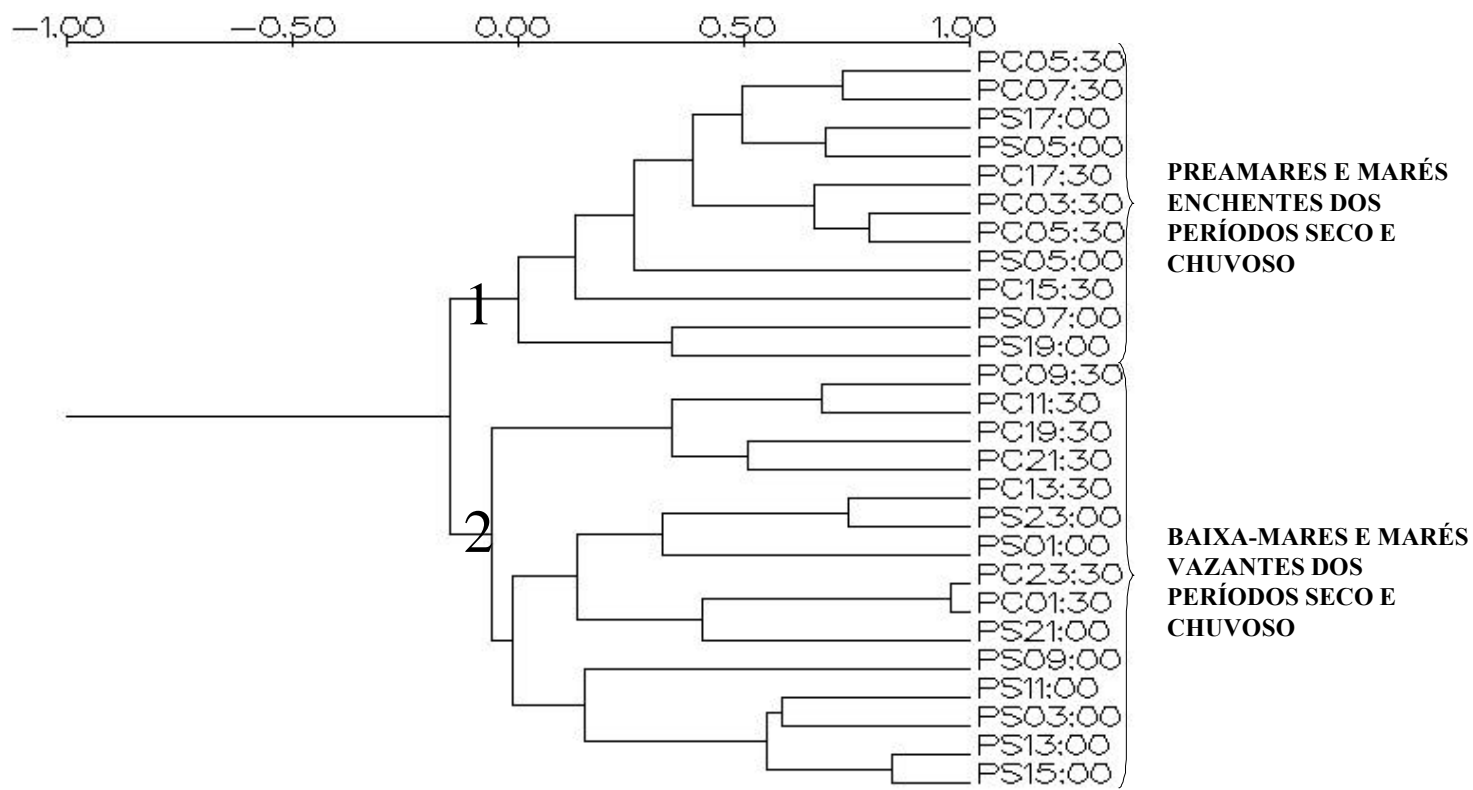

Figura 5. Dendrograma da associação das amostras no estuário do rio Ipojuca, durante os perídos chuvoso = PC (agosto/90) e seco $=$ PS (janeiro/91).

mento das diatomáceas, que se caracterizaram como o grupo mais diversificado, estando constituído principalmente por espécies litorais e eurialinas. A presença dessas espécies está condicionada ao fato de serem organismos característicos de ambiente eutrófico (Tundisi 1970).

A abertura feita nos recifes permitiu a penetração do fluxo marinho, favorecendo também o desenvolvimento de espécies de dinoflagelados características de águas oceânicas, as quais encontraram na área condições de se desenvolverem, contribuindo com $27,41 \%$ da população, enquanto que, antes da construção do Porto, eram representados por apenas 3,33\% (Eskinazi-Leça \& Koening 1985/86).

$\mathrm{O}$ aumento da biodiversidade pode ser interpretado como um impacto positivo quanto à composição florística, em virtude da presença de espécies de origens diferentes, ou seja, litorais e maior intrusão de dinoflagelados oceânicos, porém, por serem espécies especialistas, não sobrevivem na área.

Por outro lado, antes da construção do Porto eram reconhecidas 68 espécies de microal- gas, representadas por 60 diatomáceas, 5 clorofíceas e 3 cianofíceas (Eskinazi-Leça \& Koening 1985/86). Após a construção do Porto, aumentou a diversidade para 97 espécies, com a ocorrência de 72 diatomáceas, 5 clorofíceas, 11 dinoflagelados, 8 cianofíceas e 1 euglenofícea. Além disso, predominavam, como na maioria dos estuários brasileiros, espécies marinhas planctônicas neríticas, porém, após a construção do Porto, foi possível se constatar o desaparecimento de algumas ou mesmo uma diminuição na abundância de espécies como: Chaetoceros affinis var. willei, Chaetoceros rostratus, Coscinodiscus granii e Leptocylindrus danicus, consideradas frequientes e abundantes (Eskinazi-Leça \& Koening 1985/86).

O impacto foi negativo no que se refere ao número de células por litro. Antes da construção do Porto, o número de células atingia valor mínimo de 416.000 cel. $^{-1}{ }^{-1}$ máximo de 5.748 .000 cel.11 (Koening \& Eskinazi-Leça 1991). Após a construção do porto, estes valores decresceram para o mínimo de 142.000 cel. $^{-1} \mathrm{e}$ o máximo de 1.789 .000 cel. $^{-1}$, correspondendo a uma redução aproximada de $70 \%$. 
Para Bohlen et al. (1979), as dragagens e construção de canais representam uma fonte significante de sedimentos em suspensão e de contaminantes associados, e estas alterações físicas resultam na destruição de habitats e alterações hidrológicas, principalmente no que se refere a mudanças na circulação e desenvolvimento de águas anóxicas. Portanto, a ressuspensão de partículas pode favorecer o crescimento do fitoplâncton, pois estes são carreados periodicamente para a zona eufótica ou ao contrário, pode reduzir o crescimento, pela diminuição da luz e aumento da turbidez.

A grande quantidade de material em suspensão no estuário do rio Ipojuca, que provocou uma diminuição da transparência da água, notadamente durante o período chuvoso, quando é bem maior o aporte de substâncias alóctones, condicionou a diminuição da densidade fitoplanctônica. $\mathrm{O}$ maior desenvolvimento do fitoplâncton ocorreu no período seco, quando é maior a intensidade luminosa. As variações nictemerais no número de células, devem-se às correntes de marés, muito mais do que à intensidade luminosa, uma vez que, durante o período seco, ocorreram dois picos diários (diurno e noturno), coincidindo com as marés enchentes.

Segundo Devassy \& Goes, (1988), qualquer distúrbio no ambiente produz mudanças em muitas variáveis de crescimento de um organismo que freqüentemente leva a comunidade a se tornar reorganizada. Certas adaptações morfológicas e fisiológicas permitem uma espécie florescer, porém, mudanças abruptas levam à substituição de um grupo de organismos por outros ou a diminuição de sua taxa reprodutiva.

Por esta razão, pode-se afirmar que os constantes impactos na área levaram à mudanças no ecossistema e afetaram a dinâmica da estrutura da comunidade fitoplanctônica.

\section{Referências Bibliográficas}

Amaral, A. J. R. \& Menor, E. A. A. 1979. Sequência vulcano-sedimentar cretácea da região de SuapePE : interpretação faciológica e considerações metalogenéticas. Pp. 251-269. In: Simpósio de Geologia do Nordeste. Sociedade Brasileira de Gelogia, Recife.

Bohlen, W. F.; Cunhdy, D. F.\& Tramontano, J. M. 1979. Suspended material distribution in the wake of estuarine channel dredging operations. Estuarine and Coastal Marine Science 9( 6): 699-711.

Braga, R. A. P.; Moura, H. F. \& Duarte, M. T. 1989. Impactos ambientais sobre a estrutura do manguezal de Suape. Pp . 32-42. In: UNIVERSIDADE FEDERAL DE PERNAMBUCO. Departamento de Biologia Geral. Laboratório de Ecologia. Projeto Avaliação de Impactos Ambientais em Zonas Estuarinas de Pernambuco. Recife.

Cavalcanti, L. B.; Coelho, P. A.; Eskinazi-Leça, E. et al. 1980. Condiciones ecológicas en el area de Suape (Pernambuco-Brasil). Pp. 243-256. In: Seminario sobre el Estudio Cientifico e Impacto Humano en el Ecossistema de Manglares. UNESCO. Cali.

Cobra, R. Q. 1967. Geologia da região do cabo de Santo Agostinho, Pernambuco. Boletim Divisão de Fomento da Produção Mineral, 142: 1-42.

CPRH (COMPANHIA PERNAMBUCANA DE RECURSOS HÍDRICOS) 1995 . Relatório das indústrias e carga potencial, remanescente e equivalente da bacia do rio Ipojuca. Recife, não paginado.

CONDEPE (Instituto de Desenvolvimento de Pernambuco) 1980. Perfil fisiográfico das bacias hidrográficas do Estado de Pernambuco. Recife, v.1.

CONDEPE (Instituto de Desenvolvimento de Pernambuco) 1983. Caracterização do complexo estuarino-lagunar da área de Suape (PernambucoBrasil) : síntese ecológica, Recife, v. 1.

Costa, W. D. \& Costa, W. D. 1977. Estudos geológicos e geotectônicos da área portuária. Recife. Relatório final.

Day Jr., J. W.; Hall, C. A. S.; Kemp, W. M., et al. 1989. Estuarine ecology. John Willey \&Sons, New York. $556 \mathrm{p}$.

Devassy, V. P. \& Goes, J. I. 1988. Phytoplankton communities structure and sucession in a tropical estuarine complex (Central West Coast of India). Estuarine and Coastal Marine Science 27(6): 671-685. 
Edler, L. 1979. Recomendations on methods for marine biological studies in the Baltic Sea : phytoplankton and chlorophyll. The Baltic Marine Biologists 5:1-38.

Eskinazi-Leça, E. \& Koening, M. L. 1985/86. Distribuição das diatomáceas (Bacillariophyceae) na área de Suape (Pernambuco-Brasil). Trabalhos Oceanográficos da Universidade Federal de Pernambuco 19: 73-100.

Ferrario, M.; Sars, E. \& Sala, S. 1995. Metodologia básica para el estudio del fitoplancton con especial referencia a las diatomaceas. Pp. 1-24. In: Alvear, K., Ferrario, M., Oliveira Filho, E., C., \& Sar, E. (Eds.). Manual de métodos ficológicos. Universidad de Concepción, Chile

Grasshof, K.; Ehrhardt, M. \& Kremling, K. 1983. Methods of seawater analysis. $2 \mathrm{ed}$. Verlag Chemie, New York .

Hasle, G.R. 1978. The inverted-microscope methods. Pp. 88-96. In: Sournia, A. (Ed.). Phytoplankton manual. UNESCO, Paris.

Hasle, G.R. 1983. The current status of the diatom genus Coscinodiscus Ehrenberg 1839. Bot Mus. Rapp. 33 : 27-32.

Hasle, G. R. \& Syvertsen, E. E. 1997. Marine diatoms. In: Thomas, C.R. Identifying marine phytoplankton. San Diego: Academic Press, p.5-385.

Koening, M. L. 1983. Biomassa e fracionamento do fitoplâncton em viveiros de cultivo de peixes na Ilha de Itamaracá (Pernambuco-Brasil). Dissertação de Mestrado. Universidade Federal de Pernambuco, Recife.

Koening, M. L \& Eskinazi-Leça, E. 1991. Aspectos quantitativos do fitoplâncton na área estuarina de Suape (Pernambuco). Pp.55-60. In: Anais 4 Encontro Brasileiro de Plâncton, Universidade Federal de Pernambuco, Recife.

Koening, M. L.; Eskinazi-Leça, E. \& Carvalho, F. A. 1996. Análise ecológica da diatomoflora do estuário do rio Ipojuca (Suape-PernambucoBrasil). Trabalhos Oceanográficos da Universidade Federal de Pernambuco 24:61-77.

Lange, C. B.; Hasle, G. R. \& Syversten, E. E. 1992. Seasonal cycle of diatoms in the Skagerrak, North Atlantic, with emphasis on the period 1980-1990. Sarsia 77: 173-187.

Legendre, L. \& Legendre, P. 1984. Ecologie Numérique. 2. La structure des données écologiques. Quebec, Masson Presses de L'Université du Quebec. 335p. 2éme éd. (Collection d'Écologie, 13).

Lima, D. A. 1978. O projeto Suape e sua vegetação.
Recife : CONDEPE, 18 f. (Comunicação técnica, 2) Lima, D. A. \& Costa, J. T. M. 1978. Flora e vegetação terrestres da área Programa Suape. Recife : CONDEPE, $24 \mathrm{f}$. (Comunicação técnica, 5).

Loeb, S. L. \& Spacie, A. 1994. Biological monitoring of aquatic systems. Lewis Publishers, London, 381p.

Maciel, E. A. 1968. Contribuição à geologia geral de Ipojuca (PE). Recife, Universidade Federal de Pernambuco, $57 \mathrm{f}$. Relatório final de geologia de campo.

Melo, M. L. 1958 . Paisagens do nordeste de Pernambuco e Paraíba. Ed. Nacional, Rio de Janeiro, $325 \mathrm{p}$.

Melo Filho, J. A. S. 1977. Caracterização da situação atual da área Programa Suape sob o ponto de vista de poluição ambiental. Recife : CONDEPE, $15 \mathrm{~F}$. (Comunicação Técnica, 1).

Mello, A. A. \& Siqueira, L. P. 1972. Levantamento geológico da faixa costeira sul de Pernambuco. Convênio CNEN/UFPE. Relatório final. Recife, 28p.1 mapa anexo.

Moreira-Filho, H.; Eskinazi-Leça, E. \& ValenteMoreira, T. M. 1994/95. Avaliação taxonômica e ecológica das diatomáceas (Chrysophyta, Bacillariophyceae) marinhas e estuarinas nos estados do Espírito Santo, Bahia, Sergipe e Alagoas, Brasil. Biologica Brasilica 6(1/2): 87 110, Volume Especial.

Moreira-Filho, H.; Valente-Moreira, I. T.; SouzaMosimann, R. M., et al. 1990. Avaliação florística e ecológica das diatomáceas (Chrysophyta, Bacillariophyceae) marinhas e estuarinas nos estados do Paraná, Santa Catarina e Rio Grande do Sul. Estudos de Biologia 25: 5-48.

Neumann-Leitão, S. 1994. Impactos antrópicos na comunidade zooplanctônica estuarina. Porto de Suape-PE-Brasil. Tese Doutorado. Universidade de São Paulo, São Carlos.

Neumann-Leitão, S. 1986. Sistemática e ecologia dos rotíferos (Rotatoria) planctônicos da área estuarina lagunar de Suape-Pernambuco (Brasil). Recife, 261 f. Dissertação (Mestrado em Oceanografia Biológica) - Departamento de Oceanografia, Universidade Federal de Pernambuco.

Neumann-Leitão, S.; Koening, M. L .; Macêdo, S. J.; Medeiros, C.; Muniz, K. \& Feitosa, F. A. N. 1999. Plankton disturbance at Suape estuarine areaPernambuco-Brazil after a Port Complex implantation. pp. 47-56. In: (Usó, J. L., Brebbia, C. A. ed.). Second International Conference on Ecosystems and Sustainable Development. Greece. 
WIT Press, Boston.

Neumann, V. H. M. L. 1991. Geomorfologia e sedimentologia quaternária da área de Suape, Pernambuco (Brasil). Recife, 95 f. Dissertação (Mestrado em Geociências) - Departamento de Gelogia, Centro de Tecnologia, Universidade Federal de Pernambuco.

Neumann, V. H.; Medeiros, C.; Parente, L.; NeumannLeitão, S.\& Koening, M. L., 1998. Hydrodynamism, sedimentology, geomorphology and plankton changes at Suape area (Pernambuco-Brazil) after a Port Complex Implantation. Anais Academia Brasilleira de Ciências 70(2): 313-323.

Nimer, E. 1979. Pluviometria e recursos hídricos dos estados de Pernambuco e Paraíba. Rio de Janeiro : SUOREN, $117 \mathrm{p}$.

Paranaguá, M. N. 1985/86. Zooplankton of the Suape area (Pernambuco-Brazil). Trabalhos Oceanográficos da Universidade Federal de Pernambuco, 19: 113-124.

Poole, H. H.\& Atkins, W. R. G. 1929. Photoeletric measurements of submarine ilumination throughout the year. Journal Marine Biological Association United Kingdom, 16: 297-325.
Rohlf, F. J. \& Fisher, D. L., 1968. Test for hierarchical structure in random data sets. Systematic Zool., 17:407-412.

Santos, M. A. \& Costa, W. D.1974. Complexo industrial de Suape: estudo hidrogeológico preliminar. Pp.4969. In: Simpósio de Geologia do Nordeste. Sociedade Brasileira de Geologia do Nordeste, Recife.

Shannon, C. E. 1948. A mathematical theory of communication. Bulletin of System Technology Journal 27: 379-423.

Strickland, J. D. H. \& Parsons, T. R. 1972. A manual of seawater analysis. Bulletin Fisheries Research Board of Canada 125: 1-205.

Tundisi, J. G. O plâncton estuarino. 1970. Contribuições Avulsas do Instituto Oceanográfico de São Paulo, 19: 1-22.

Unesco. 1973. International oceanographic tables. Wormley 2, 141p.

Vasconcelos Filho, A. L.; Guedes, D. S. \& Sobrinho, D. G. 1990. Taxonomia e ecologia da fauna ictiológica da área de Suape (Pernambuco-Brasil). Trabalhos Oceanográficos da Universidade Federal de Pernambuco, 21: 305-343. 